\title{
Identification and Antibiotic Susceptibility Pattern of Enterobacteriaceae Isolated from Gecko (Hemidactylus frenatus)
}

\section{*1,2TAIWO, MO; ${ }^{1}$ OYEDEMI, OT; ${ }^{1}$ ADELABU, BA; ${ }^{1}$ SHOFUNDE, AA; ${ }^{2}$ OJESOLA CO, ${ }^{1}$ ANTHONY, AC}

\author{
${ }^{I}$ Department of Microbiology, College of Natural and Applied sciences, Chrisland University, Abeokuta, Ogun State, Nigeria \\ ${ }^{2}$ Department of Microbiology, College of Biosciences, Federal University of Agriculture, Abeokuta, Ogun State, Nigeria \\ *Corresponding Author Email: taiwomikeo@gmail.com
}

\begin{abstract}
Diseases and infections which are naturally transmitted between animals and humans are of major concern worldwide. Geckos (Hemidactylus frenatus) are known to be potential reservoirs of many zoonotic enteropathogens. This study was designed to isolate, identify, and evaluate the antibiotic susceptibility pattern of Enterobacteriaceae from Geckos. Using standard microbiological procedures, bacteria were isolated from 138 intestinal samples of Hemidactylus frenatus collected from different sampling sites. A total of 20 bacterial species of 9 different genera were identified using automated Colorimetry VITEK 2 system. The percentage occurrences were Enterobacter aerogenes (35\%), Proteus mirabilis (15\%), Salmonella ser paratyphi B (10\%), Serratia fonticola (10\%), Enterobacter kobei (10\%), Raoultella ornithinolytica (5\%), Sphingomonas paucimobilis (5\%), Acinetobacter baumannii, (5\%) and Burkholderia cepacia (5\%). Results obtained from the antibiotic susceptibility pattern according to CLSI guidelines revealed that all the 20 bacterial species have varying rate of resistance with $20(100 \%)$ showing resistance to Ciprofloxacin (CPX), 20 (100\%) Pefloxacin (PEF), 19 (95\%), Augmentin (AU), 11 (55\%) Cotrimoxazole (CXT), 10 (50\%) Streptomycin (S), 9 (45\%) Chloramphenicol (CH), 6 (30\%) Gentamycin (CN), 3 (15\%) Ofloxacin (OFX). This study revealed that Enterobacteriaceae in the intestine of Geckos are multidrug resistant and are potentially harmful when in contact directly or indirectly with humans. It becomes important to educate people on the importance of personal hygiene in order to eradicate Geckos from our environment.
\end{abstract}

\section{DOI: https://dx.doi.org/10.4314/jasem.v25i10.4}

Copyright: Copyright $\odot 2021$ Taiwo et al. This is an open access article distributed under the Creative Commons Attribution License (CCL), which permits unrestricted use, distribution, and reproduction in any medium, provided the original work is properly cited.

Dates: Received: 22 August 2021; Revised: 17 September 2021; Accepted: 06 October 2021

Keywords: Disease, Antibiotics, Hemidactylus frenatus, Enterobacteriaceae

Bacteria are widespread in the environment and have evolved a variety of interactions with animals including those inhabited in human dwellings (Feldhaar, 2011). The presence of insect pests is common and affects all human habitations, creating conditions that are favorable to many pests that can harbor pathogens (Bertone et al., 2016; Leong et al., 2017). Geckos (Hemidactylus frenatus) belong to the reptilian family Geckkonidae which can be wild or non-wild type. They are nocturnal animals found within human habitation where they find shelter, heat and food; feeding on other smaller insects and left over food substances (Nwachukwu et al., 2014). Generally, Reptiles have been reported to carry bacteria agents in their digestive tract without manifesting any associated symptom other than serving as sources of contamination and disease vector to humans (Ajayi et al., 2015). Diseases can be transmitted to humans indirectly or directly. The indirect method can be the transmission of pathogens (organisms that causes diseases) through the ingestion of fecal contaminated food and water while the direct method can be from person to person etc. (Whiley et al., 2017). Few researchers who have studied Geckos as a reservoir of pathogens have reported zoonotic enteropathogens such as Edwardsiella tarda, Citrobacter freundii, Klebsiella pneumonia, Clostridium Intermedius, Erwinia herbicola, Enterobacter cloacae (Singh et al., 2013, Nwachukwu et al., 2014;), Shigella sonnei, Enterobacter species, Serratia marcescens, Proteus spp., Escherichia coli including non-typhoidal salmonellae (Callaway et al., 2011; Gwen and Saleha, 2013; Arnafia et al., 2016). These microorganisms are Gram-negative bacterium of the Enterobacteriaceae family which have been categorized as the major global causes of diarrheal, ulcerative stomatitis, pneumonia, cutaneous lesions, septicemias, caseated abscesses, and are associated with consumption of contaminated food products of animal origin (WHO, 2018; Bjelland et al., 2020). It has been observed that Enterobacteriaceae obtained from both food animals and humans shows increasing antibiotic resistance rates (Hakanen et al., 2015). For example, Salmonella enterica and Escherichia coli have been widely 
reported to have multiple antibiotic resistances of which most of the strains are zoonotic in origin (Ogunleye and Carlson, 2010; Singh et al., 2013). Majority of multiple antibiotic resistance strains acquired their resistance in the food-animal host, causing human infections through the food chain. According to Yakubu et al. (2011); Omitola and Taylor-Robinson (2020); approximately $60 \%$ of the several infectious microorganisms that causes emerging and re-emerging diseases are confirmed to be zoonotic. However, of all the animals that live in close proximity with humans and liable to harbor pathogens, Geckos (Hemidactylus frenatus) are the least studied. In Nigeria, Geckos comes with several myths which prevents their eradication despites their massive invasions of homes. The Common House Gecko have a simple life process of feeding on smaller insects such as cockroach, housefly, weevils, spiders, ants etc as their food, which raises their potentials of being a reservoir for pathogens. Geckos could be vectors of opportunistic bacteria (an organism that was initially a commensal or mutualistic and turns out to cause a disease) or true pathogen, possessing properties that enables them to overcome the body defenses and infect the tissue of a normal healthy subject producing disease. Their frequent excretion of ingested food through their faecal droppings may also serve as a vector for the transmission of enteric pathogens which can be risky to human health. Though earlier studies which focused more on their intestinal droppings were impressive, however, bacteria detected in intestinal tract may not always be present in the excreta probably due to several competitive factors in the posterior part of gastrointestinal tracts, hence, the isolation from intestinal tract in this study. Researchers have reported several other reptiles as host of drug resistant bacteria (Ogunleye and Carlson, 2010; Singh et al., 2013; Ajayi et al., 2015), little has been known of Geckos. However, no research has been able to identify drugresistant bacteria isolated from Gecko using VITEK 2 system. VITEK 2 system is a user-friendly machine incorporated software with bi-directional interface, epidemiology report module, and comprehensive database used for the identification of bacteria and yeast, and epidemiologic trending and reporting (Maina and Kagotho, 2014). The VITEK 2 system uses an identification technology known as Advanced Colorimetry that enables the identification of routine clinical isolates and provides high discrimination between species (Wani et al., 2016). This study aimed to isolate, characterize and evaluate the antibiotic susceptibility pattern of Enterobacteriaceae from the intestinal tract of Geckos (Hemidactylus frenatus).

\section{MATERIALS AND METHODS}

Study site: Gecko (Hemidactylus frenatus) samples for the study were collected randomly from different sites in Abeokuta metropolis, Ogun state, Nigeria. The targeted sites were indoors and outdoors such as Kitchen, Animal House, Corridor, Store, Hospital, Toilet, etc where there are possibilities of direct or indirect contact with Humans. Hemidactylus frenatus is known to be carnivorous (insectivorous) and nocturnal animals, so they are captured mostly at nights.

Sample Collection and Storage: A total of one hundred and thirty-eight (138) samples of Hemidactylus frenatus were aseptically collected from different sites. The Geckos were placed in a perforated sterile sample bottle to allow enough air-flow for respiration and transferred into sterile plastic bags. Each sample bottle contains one Gecko and then transported to the Microbiology Laboratory, Chrisland University, Abeokuta for further analysis.

Isolation of Microorganisms: Hemidactylus frenatus was surface sterilized using iodine, and then $70 \%$ ethanol. Dissection for intestinal examination was carried out using sterile dissecting kit. The body cavity was cut open in a ventral longitudinal position to expose the intestinal system. The intestinal tract was carefully separated from the attached tissues. The separated intestine that ends in the cloaca was removed using a sterilized forceps and placed in a sterile swab stick containing already prepared peptone water. The same procedure was carried out for all other samples. All samples were incubated in a shaker incubator for 18 hours at $37^{\circ} \mathrm{C}$. After incubation, each sample was streaked on plates containing already prepared MacConkey agar and Eosin Methylene Blue agar respectively. Plates were then incubated at $37^{\circ} \mathrm{C}$ for 24 hours.

Purification of Bacterial isolates: Pure cultures of the bacterial isolates were obtained by series of subculturing on the corresponding medium. Isolates with different morphological appearances were selected and purified by streaking on corresponding medium plates until pure cultures were obtained. All pure cultures of bacterial isolates were inoculated and maintained on the corresponding agar slants and stored at $4^{\circ} \mathrm{C}$ in the refrigerator.

Phenotypic Characterization of Bacterial isolates: The bacteria isolates were subjected to standard microbiological methods such as morphological characteristics of the colony (colour, surface, margin, and elevation) and Gram staining to differentiate Gram-negative and Gram-positive bacteria. 
Biochemical tests, including Catalase test, Citrate utilization test, Voges-Proskaeur test, Urease test, Indole test, Triple Sugar iron test, sugar fermentation test, and methyl-red test were also carried out on the isolates (Fawole and Oso, 1998; Cheesbrough, 2006). The morphological and biochemical characteristics of the isolates were examined according to Bergey's Manual of Determinative Bacteriology.

Antibiotic Susceptibility Testing: The Kirby Bauer disc diffusion agar technique was used to determine the antibiotic susceptibility of the isolated organisms. Mueller-Hinton agar was prepared according to the manufacturer's instruction. An 18-24 hours old test organism was standardized by diluting to 0.5 Mcfarland's standard. A sterile swab stick was inserted into the inoculum and inoculated by spreading evenly onto the sterile Mueller-Hinton agar plate. The inoculated plates were then allowed to dry for few minutes at room temperature with the lid closed. After this, antibiotic-impregnated discs of known concentrations; Cotrimoxazole $(30 \quad \mu \mathrm{g})$, Chloramphenicol $(30 \mu \mathrm{g})$, Ciprofloxacin $(30 \mu \mathrm{g})$, Augmentin $(10 \mu \mathrm{g})$, Gentamycin $(30 \mu \mathrm{g})$, Pefloxacin $(30 \mu \mathrm{g})$, Ofloxacin $(10 \mu \mathrm{g})$, Streptomycin $(30 \mu \mathrm{g})$ were carefully seeded on the inoculated Mueller- Hinton agar plates using sterile forceps. The plates were then incubated at $37^{\circ} \mathrm{C}$ for $18-24$ hours. The diameters of the zones of inhibition were measured and interpreted following guidelines recommended by the Clinical and Laboratory Standards Institute (CLSI) (Moses et al., 2018).

VITEK 2 Identification of Bacterial isolates: Bacteria identification were performed using the Vitek Gramnegative card. The card is allowed to come to room temperature before opening the package liner. The Vitek tubes were aseptically filled with $3 \mathrm{~mL}$ of sterile Vitek saline. Sterile cotton swabs were used to prepare a homogenous organism suspension by transferring isolated colonies from a pure culture. The suspension was adjusted to $0.5 \mathrm{McF}$ arland turbidity using the densitometer. The suspension was placed in the Vitek cassette and used directly for identification purposes. The straw of the Vitek 2 card was inserted into the inoculated suspension tubes within 30 minutes of suspension preparation. The cassette was placed in the filler box of the Vitek unit and allowed to load. The Vitek 2 machine automatically processed the cards and ejected them into the waste bin collection after the cards had been processed (Ksiazczyk et al., 2016).

Statistical analysis of data: Data were analysed using Statistical Package for Social Sciences (SPSS) version 16.0 for Windows (SPSS, Chicago IL, U.S.A). The means of the data obtained were analysed by analysis of variance (ANOVA), means were separated using the Student-Newman-Keuls (SNK) test at $\alpha=0$ (Akintokun and Taiwo, 2016).

\section{RESULTS AND DISCUSSION}

The Total Bacterial Counts (TBC) obtained from different samples grown on Eosin Methylene Blue (EMB) and MacConkey agar respectively were shown in table 1. The Total Bacterial Counts grown on both media were significantly different from each other. On EMB medium, bacteria count from MH $\left(2.25 \times 10^{2}\right)$ was significantly higher than those obtained from $\mathrm{AH}$ $\left(2.10 \times 10^{2}\right)$, which was significantly higher than AUD $\left(2.04 \times 10^{2}\right)$. This was followed by CAF $\left(1.99 \times 10^{2}\right)$ which was significantly higher than ST $\left(1.97 \times 10^{2}\right)$, SP2 $\left(1.84 \times 10^{2}\right)$, SP1 $\left(1.60 \times 10^{2}\right)$ and E3 $\left(1.38 \times 10^{2}\right)$ respectively. The least bacterial count was obtained in SB2 with a bacterial count of $1.27 \times 10^{2}$. (Table 1). However, bacteria count obtained grown on MAC from LAB $\left(2.41 \times 10^{2}\right)$ was significantly higher than those obtained from FH2 $\left(2.09 \times 10^{2}\right)$, which was significantly higher than TS $\left(2.02 \times 10^{2}\right)$. This was followed by CR3 $\left(1.73 \times 10^{2}\right)$ which is significantly higher than SB3 $\left(1.66 \times 10^{2}\right)$, SB1 $\left(1.50 \times 10^{2}\right)$, E4 (1.44 $\left.\mathrm{x} 10^{2}\right)$, HK1 $\left(1.23 \times 10^{2}\right)$, SB4 $\left(1.06 \times 10^{2}\right)$ and E1 (1.03 $\mathrm{x} 10^{2}$ ) respectively. The least bacterial count was obtained in HP1 with a total bacterial count of 1.02 $\mathrm{x} 10^{2}$. (Table 1)

Table 1: Total Bacterial counts isolated from Hemidactylus frenatus grown on Eosin Methylene Blue and Mac-Conkey Agar medium

\begin{tabular}{llll}
\hline $\begin{array}{l}\text { Methylene Blue } \\
\text { Sample code }\end{array}$ & $\begin{array}{l}\text { Agar (MBA) } \\
\text { Bacterial counts } \\
\left(\mathbf{1 0}^{\mathbf{2}}\right)(\mathbf{C F U} / \mathbf{m l})\end{array}$ & $\begin{array}{l}\text { Mac-Conkey } \\
\text { Sample code }\end{array}$ & $\begin{array}{l}\text { Agar (MCA) } \\
\text { Bacterial counts } \\
\left(\mathbf{1 0}^{\mathbf{2}}\right)(\mathbf{C F U} / \mathbf{m l})\end{array}$ \\
\hline SB2 & $1.27 \pm 1.73$ & SB3 & $1.66 \pm 3.53$ \\
AUD & $2.04 \pm 4.58$ & SB4 & $1.06 \pm 3.93$ \\
SP1 & $1.60 \pm 5.36$ & SB1 & $1.50 \pm 2.40$ \\
MH & $2.25 \pm 3.52$ & FH2 & $2.09 \pm 4.70$ \\
E3 & $1.38 \pm 6.80$ & TS & $2.02 \pm 1.76$ \\
CAF & $1.99 \pm 5.78$ & LAB & $2.41 \pm 2.19$ \\
AH & $2.10 \pm 6.65$ & HK1 & $1.23 \pm 3.18$ \\
SP2 & $1.85 \pm 4.33$ & E4 & $1.44 \pm 3.06$ \\
ST & $1.97 \pm 4.05$ & E1 & $1.03 \pm 3.18$ \\
& & CR3 & $1.73 \pm 4.23$ \\
& & HP1 & $1.02 \pm 2.52$ \\
\hline
\end{tabular}


Results are mean values \pm standard error of mean for three replicates according to Student Newman-Keuls (SNK) test at $\alpha=0.05$.

The biochemical characterization of bacterial isolates is shown in table 2. A total of twenty (20) bacteria were isolated and presented for characterization. From the result, all bacterial isolates were Gram-negative with an indication of pink color, while the shape of the bacteria were all rods. The catalase test revealed that all bacterial isolates were catalase-positive indicating the production of the enzyme catalase except GE15 which is catalase-negative. The result from indole test showed that eleven (11) bacterial isolates (GE1, GE2, GE3, GE4, GE6, GE9, GE10, GE11, GE17, GE18, GE20) of the twenty (20) samples were positive while the other nine (GE5, GE7, GE8, GE12, GE13, GE14, GE15, GE16, GE19) were negative. Sixteen (16) isolates with the code GE2, GE3, GE5, GE6, GE7, GE8, GE9, GE10, GE11, GE12, GE13, GE14, GE15, GE18, GE19 and GE20 were all methyl red positive, while the other four isolates (GE1, GE4, GE16, GE17) were negative. Only isolate GE1 was Voges-Proskauer positive while others were negative. Similarly, Only
GE15 was able to utilize citrate (positive) while others could not. The results from the sugar fermentation test showed that all bacterial isolates were glucose positive indicating their ability to ferment glucose. For sucrose test, fifteen (15) isolates (GE3, GE4, GE5, GE7, GE8, GE9, GE10, GE12, GE14, GE15, GE16, GE17, GE18, GE19, GE20) were positive while the other five (5) isolates (GE1, GE2, GE6, GE11, and GE13) were sucrose negative. All bacterial isolates also showed their inability to ferment Lactose except GE3, GE7, GE9, GE10, and GE20 which were able to ferment lactose. The result for hydrogen sulfide test $\left(\mathrm{H}_{2} \mathrm{~S}\right)$ showed that all bacterial isolates were positive except GE4, GE12, GE15, GE16, and GE17 which were negative. The test for the production of gas revealed that all bacterial isolates were able to produce gas except GE1, GE4, GE15 and GE17 which were not able to produce gas. All bacterial isolates showed positive for urease test except GE15 which was urease negative (Table 2).

Table 2: Biochemical Characterization of Bacteria Isolates from Hemidactylus frenatus

\begin{tabular}{|c|c|c|c|c|c|c|c|c|c|c|c|c|c|}
\hline 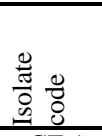 & 喆 & $\begin{array}{l}\frac{0}{0} \\
\frac{\pi}{2} \\
\sum^{0} \\
\text { od }\end{array}$ & 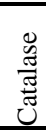 & $\frac{0}{\circ}$ & 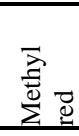 & 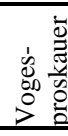 & $\stackrel{\mathscr{U}}{ت}$ & 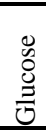 & 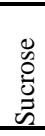 & 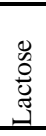 & $\tilde{I}$ & $\tilde{\Xi}$ & 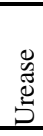 \\
\hline GE 1 & - & Rod & + & + & _- & + & + & + & - & _- & + & _ & + \\
\hline GE 2 & - & Rod & + & + & + & _ & + & + & _ & _ & + & + & + \\
\hline GE 3 & - & Rod & + & + & + & _ & + & + & + & + & + & + & + \\
\hline GE 4 & _ & Rod & + & + & _ & _ & + & + & + & _ & - & - & + \\
\hline GE 5 & _- & Rod & + & - & + & - & + & + & + & _- & + & + & + \\
\hline GE 6 & - & Rod & + & + & + & - & + & + & - & - & + & + & + \\
\hline GE 7 & - & Rod & + & - & + & _ & + & + & + & + & + & + & + \\
\hline GE 8 & - & Rod & + & _ & + & _- & + & + & + & _- & + & + & + \\
\hline GE 9 & - & Rod & + & + & + & - & + & + & + & + & + & + & + \\
\hline GE 10 & - & Rod & + & + & + & _ & + & + & + & + & + & + & + \\
\hline GE 11 & - & Rod & + & + & + & - & + & + & _ & - & + & + & + \\
\hline GE 12 & - & Rod & + & - & + & - & + & + & + & - & - & + & + \\
\hline GE 13 & - & Rod & + & - & + & - & + & + & - & _ & + & + & + \\
\hline GE 14 & _ & Rod & + & _ & + & _ & + & + & + & _- & + & + & + \\
\hline GE 15 & _ & Rod & - & - & + & - & - & + & + & - & - & - & - \\
\hline GE 16 & _ & Rod & + & _ & _ & _ & + & + & + & _ & _ & + & + \\
\hline GE 17 & _ & Rod & + & + & _ & _ & + & + & + & _ & _ & - & + \\
\hline GE 18 & - & Rod & + & + & + & - & + & + & + & - & + & + & + \\
\hline GE 19 & - & Rod & + & - & + & - & + & + & + & 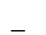 & + & + & + \\
\hline GE 20 & 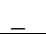 & Rod & + & + & + & _ & + & + & + & + & + & + & + \\
\hline
\end{tabular}

The bacterial isolates were presented for a confirmatory identification using VITEK 2 system. Results obtained from the automated method showed that Isolates GE1, GE5 and GE8 were Proteus mirabilis, Isolate GE2 was Raoultella ornithinolytica, Isolates GE3, GE4, GE9, GE10, GE12, GE17 and GE20 were identified as Enterobacter aerogenes, Isolates GE6 and GE11 were identified as Salmonella ser paratyphi B, isolates GE7 and GE19 were identified as Serratia fonticola, isolates GE13 and GE14 were identified as Enterobacter kobei. Isolates
GE15, GE16 and GE18 were identified as Sphingomonas paucimobilis, Acinetobacter baumannii, Burkholderia cepacia respectively (Table 3).

The prevalence of Enterobacteriaceae from different sample sites is shown in Table 4. Three (3) Enterobacteriaceae namely Salmonella ser paratyphi $B$, Enterobacter aerogenes and Acinetobacter baumannii were isolated from Kitchens (15\%) while four (Proteus mirabilis, Enterobacter aerogenes, Salmonella ser paratyphi B and Burkholderia cepacia) 
were isolated from outdoors (20\%). Serratia fonticola was only isolated from Animal houses (5\%) while Raoultella ornithinolytica and Enterobacter kobei were isolated from Stores (10\%). Four (4) Enterobacteriaceae namely Enterobacter aerogenes,
Proteus mirabilis, Sphingomonas paucimobilis and Serratia fonticola were isolated from Hospitals (20\%) while Enterobacter aerogenes and Enterobacter kobei were isolated from Toilets $(10 \%)$.

Table 3: Identification of Bacterial isolates using VITEK 2 system

\begin{tabular}{|c|c|c|}
\hline Isolate Codes & Identified organisms & Confidence level \\
\hline GE 1 & Proteus mirabilis & Good identification \\
\hline GE 2 & Raoultella ornithinolytica & Good identification \\
\hline GE 3 & Enterobacter aerogenes & Very good identification \\
\hline GE 4 & Enterobacter aerogenes & Good identification \\
\hline GE 5 & Proteus mirabilis & Good identification \\
\hline GE 6 & Salmonella ser paratyphi $B$ & Excellent identification \\
\hline GE 7 & Serratia fonticola & Very good identification \\
\hline GE 8 & Proteus mirabilis & Good identification \\
\hline GE 9 & Enterobacter aerogenes & Very good identification \\
\hline GE 10 & Enterobacter aerogenes & Very good identification \\
\hline GE 11 & Salmonella ser paratyphi $B$ & Excellent identification \\
\hline GE 12 & Enterobacter aerogenes & Very good identification \\
\hline GE 13 & Enterobacter kobei & Excellent identification \\
\hline GE 14 & Enterobacter kobei & Very good identification \\
\hline GE 15 & Sphingomonas paucimobilis & Acceptable identification \\
\hline GE 16 & Acinetobacter baumannii & Excellent identification \\
\hline GE 17 & Enterobacter aerogenes & Good identification \\
\hline GE 18 & Burkholderia cepacia & Very good identification \\
\hline GE 19 & Serratia fonticola & Good identification \\
\hline GE 20 & Enterobacter aerogenes & Very good identification \\
\hline
\end{tabular}

Table 4: Prevalence of Enterobacteriaceae in different Sample sites

\begin{tabular}{lll}
\hline Sample site & $\begin{array}{l}\text { Percentage } \\
\text { occurrence }\end{array}$ & Identified Enterobacteriaceae \\
\hline Kitchen & $15 \%$ & $\begin{array}{l}\text { Salmonella ser paratyphi B, Enterobacter } \\
\text { aerogenes, Acinetobacter baumannii } \\
\text { Proteus mirabilis, Enterobacter aerogenes, } \\
\text { Salmonella ser } \\
\text { paratyphi B, Burkholderia cepacia }\end{array}$ \\
Animal house & $5 \%$ & $\begin{array}{l}\text { Serratia fonticola } \\
\text { Raoultella ornithinolytica, Enterobacter kobei } \\
\text { Enterobacter aerogenes, Proteus mirabilis, }\end{array}$ \\
Store & $10 \%$ & $\begin{array}{l}\text { Sphingomonas paucimobilis, Serratia fonticola } \\
\text { Enterobacter aerogenes, Enterobacter kobei }\end{array}$ \\
Tospital & $20 \%$ &
\end{tabular}

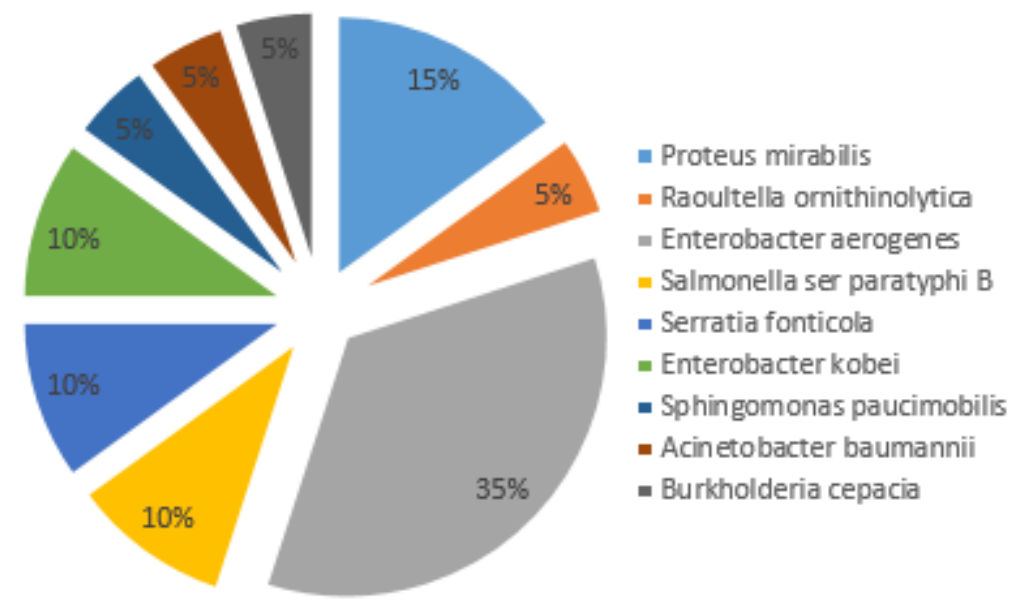

Fig 1: Frequency of Enterobacteriaceae

Figure 1 showed the frequency of Enterobacteriaceae isolated from Geckos. From the figure presented below, Enterobacter aerogenes has the highest frequency of $35 \%$. This was followed by Proteus 
mirabilis with a frequency of $15 \%$, while Salmonella ser paratyphi B, Serratia fonticola and Enterobacter kobei all has a frequency of $10 \%$ each. The least frequency of 5\% was each obtained in Raoultella ornithinolytica, Sphingomonas paucimobilis, Acinetobacter baumannii, and Burkholderia cepacia.

Evaluation of Enterobacteriaceae against selected Antibiotics: Enterobacteriaceae were tested against Cotrimoxazole (CXT), Chloramphenicol (CH), Ciprofloxacin (CPX), Augmentin (AU), Gentamycin $(\mathrm{CN})$, Pefloxacin (PEF), Ofloxacin (OFX), and Streptomycin (S) using the disk diffusion susceptibility method. Proteus mirabilis GE1 was resistant to all antibiotics except Gentamycin and Ofloxacin. Raoultella ornithinolytica GE2 was resistant to all antibiotics except Chloramphenicol, Gentamycin, and Ofloxacin. However, Enterobacter aerogenes GE3 was resistant to all the antibiotics. Enterobacter aerogenes GE4 was resistant to all antibiotics except Cotrimoxazole, Ciprofloxacin, Ofloxacin and Streptomycin. Proteus mirabilis GE5 was resistant to all antibiotics except Chloramphenicol, Gentamycin and Ofloxacin. Salmonella ser paratyphi B GE6 was resistant to all antibiotics except Cotrimoxazole, Chloramphenicol, Gentamycin, Ofloxacin and Streptomycin. Serratia fonticola GE7 was resistant to all antibiotics except Gentamycin. Proteus mirabilis GE8 was resistant to all antibiotics except Cotrimoxazole. Enterobacter aerogenes GE9 was resistant to all antibiotics except
Chloramphenicol and Ofloxacin. Enterobacter aerogenes GE10 showed resistant to all antibiotics except Ciprofloxacin, Gentamycin and Ofloxacin. Salmonella ser paratyphi $B$ GE11 was resistant to all antibiotics except Gentamycin, Ofloxacin and Streptomycin. Enterobacter aerogenes GE12 was resistant to all tested antibiotics except Cotrimoxazole, Chloramphenicol, Gentamycin, Augmentin, Ofloxacin and Streptomycin. Enterobacter kobei GE13 showed resistance to all antibiotics except Cotrimoxazole, Chloramphenicol, Gentamycin, Ofloxacin and Streptomycin. Enterobacter kobei GE14 was resistant to all antibiotics except Cotrimoxazole, Ofloxacin and Streptomycin. Sphingomonas paucimobilis GE15 showed resistance to all antibiotics except Cotrimoxazole, Gentamycin, Ofloxacin and Streptomycin. Acinetobacter baumannii GE16 was resistant to all antibiotics except Cotrimoxazole, Chloramphenicol, Gentamycin, Ofloxacin and Streptomycin. Enterobacter aerogenes GE17 was resistant to all antibiotics except Cotrimoxazle, Chloramphenicol, Ofloxacin and Streptomycin. Burkholderia cepacia GE18 was resistant to all antibiotics except Gentamycin, Ofloxacin and Streptomycin. Serratia fonticola GE19 showed resistance to antibiotics to all antibiotics except Chloramphenicol, Gentamycin and Ofloxacin. Enterobacter aerogenes GE20 was resistant to all antibiotics except Gentamycin and Ofloxacin (Table $5)$.

Table 5: Sensitivity of Enterobacteriaceae against Antibiotics using CLSI (Clinical and Laboratory Standard Institute) Break points

\begin{tabular}{|c|c|c|c|c|c|c|c|c|}
\hline Bacterial species & [CXT] & {$[\mathrm{CH}]$} & [CPX] & [AU] & {$[\mathrm{CN}]$} & PEF] & [OFX] & [S] \\
\hline Proteus mirabilis GE1 & $\overline{\mathrm{R}}$ & $\mathrm{R}$ & $\mathrm{R}$ & $\mathrm{R}$ & $\mathrm{S}$ & $\overline{\mathrm{R}}$ & $\mathrm{S}$ & $\mathrm{R}$ \\
\hline Raoultella ornithinolytica GE2 & $\mathrm{R}$ & $\mathrm{S}$ & $\mathrm{R}$ & $\mathrm{R}$ & $\mathrm{S}$ & $\mathrm{R}$ & $\mathrm{S}$ & $\mathrm{R}$ \\
\hline Enterobacter aerogenes GE3 & $\mathrm{R}$ & $\mathrm{R}$ & $\mathrm{R}$ & $\mathrm{R}$ & $\mathrm{R}$ & $\mathrm{R}$ & $\mathrm{R}$ & $\mathrm{R}$ \\
\hline Enterobacter aerogenes GE4 & $\mathrm{S}$ & $\mathrm{S}$ & $\mathrm{R}$ & $\mathrm{R}$ & $\mathrm{R}$ & $\mathrm{R}$ & $\mathrm{S}$ & $\mathrm{S}$ \\
\hline Proteus mirabilis GE5 & $\mathrm{R}$ & $\mathrm{S}$ & $\mathrm{R}$ & $\mathrm{R}$ & $\mathrm{S}$ & $\mathrm{R}$ & $\mathrm{S}$ & $\mathrm{R}$ \\
\hline Salmonella ser paratyphi B GE6 & $\mathrm{S}$ & $\mathrm{S}$ & $\mathrm{R}$ & $\mathrm{R}$ & $\mathrm{S}$ & $\mathrm{R}$ & $\mathrm{S}$ & $\mathrm{S}$ \\
\hline Serratia fonticola GE7 & $\mathrm{R}$ & $\mathrm{R}$ & $\mathrm{R}$ & $\mathrm{R}$ & $\mathrm{S}$ & $\mathrm{R}$ & $\mathrm{R}$ & $\mathrm{R}$ \\
\hline Proteus mirabilis GE8 & $\mathrm{S}$ & $\mathrm{R}$ & $\mathrm{R}$ & $\mathrm{R}$ & $\mathrm{R}$ & $\mathrm{R}$ & $\mathrm{R}$ & $\mathrm{R}$ \\
\hline Enterobacter aerogenes GE9 & $\mathrm{R}$ & $\mathrm{S}$ & $\mathrm{R}$ & $\mathrm{R}$ & $\mathrm{R}$ & $\mathrm{R}$ & $\mathrm{S}$ & $\mathrm{R}$ \\
\hline Enterobacter aerogenes GE10 & $\mathrm{R}$ & $\mathrm{S}$ & $\mathrm{R}$ & $\mathrm{R}$ & $\mathrm{S}$ & $\mathrm{R}$ & $\mathrm{S}$ & $\mathrm{R}$ \\
\hline Salmonella ser paratyphi B GE11 & $\mathrm{R}$ & $\mathrm{R}$ & $\mathrm{R}$ & $\mathrm{R}$ & $\mathrm{S}$ & $\mathrm{R}$ & $\mathrm{S}$ & $\mathrm{S}$ \\
\hline Enterobacter aerogenes GE12 & $\mathrm{S}$ & $\mathrm{S}$ & $\mathrm{R}$ & $\mathrm{S}$ & $\mathrm{S}$ & $\mathrm{R}$ & $\mathrm{S}$ & $\mathrm{S}$ \\
\hline Enterobacter kobei GE13 & $\mathrm{S}$ & $\mathrm{S}$ & $\mathrm{R}$ & $\mathrm{R}$ & $\mathrm{S}$ & $\mathrm{R}$ & $\mathrm{S}$ & $\mathrm{S}$ \\
\hline Enterobacter kobei GE14 & $\mathrm{S}$ & $\mathrm{R}$ & $\mathrm{R}$ & $\mathrm{R}$ & $\mathrm{R}$ & $\mathrm{R}$ & $\mathrm{S}$ & $\mathrm{S}$ \\
\hline Sphingomonas paucimobilis GE15 & S & $\mathrm{R}$ & $\mathrm{R}$ & $\mathrm{R}$ & $\mathrm{S}$ & $\mathrm{R}$ & $\mathrm{S}$ & $\mathrm{S}$ \\
\hline Acinetobacter baumannii GE16 & $\mathrm{S}$ & $\mathrm{S}$ & $\mathrm{R}$ & $\mathrm{R}$ & $\mathrm{S}$ & $\mathrm{R}$ & $\mathrm{S}$ & $\mathrm{S}$ \\
\hline Enterobacter aerogenes GE17 & $\mathrm{S}$ & $\mathrm{S}$ & $\mathrm{R}$ & $\mathrm{R}$ & $\mathrm{R}$ & $\mathrm{R}$ & $\mathrm{S}$ & $\mathrm{S}$ \\
\hline Burkholderia cepacia GE18 & $\mathrm{R}$ & $\mathrm{R}$ & $\mathrm{R}$ & $\mathrm{R}$ & $\mathrm{S}$ & $\mathrm{R}$ & $\mathrm{S}$ & $\mathrm{S}$ \\
\hline Serratia fonticola GE19 & $\mathrm{R}$ & $S$ & $\mathrm{R}$ & $\mathrm{R}$ & $\mathrm{S}$ & $\mathrm{R}$ & $\mathrm{S}$ & $\mathrm{R}$ \\
\hline Enterobacter aerogenes GE20 & $\mathrm{R}$ & $\mathrm{R}$ & $\mathrm{R}$ & $\mathrm{R}$ & $\mathrm{S}$ & $\mathrm{R}$ & $\mathrm{S}$ & $\mathrm{R}$ \\
\hline
\end{tabular}

KEY: $C X T=$ Cotrimoxazole, $C H=$ Chloranphenicol, $C P X=$ Ciprofloxacin, $A U=$ Augmentin, $C N=$ Gentamycin, $P E F=P e f l o x a c i n, ~ O F X=$ Ofloxacin, $S=$ Streptomycin, $R=$ Resistant, $S=$ Susceptible

Frequency of Enterobacteriaceae to Antibiotics sensitivity: Figure 2 shows the total number of Enterobacteriaceae that are sensitive (susceptible or resistance) to Antibiotics. From the result presented in figure 3, Cotrimoxazole (CXT) was resistant to eleven (11) Enterobacteriaceae but susceptible to only nine 
(9). Chloramphenicol $(\mathrm{CH})$ was resistant to nine (9) Enterobacteriaceae but susceptible to eleven (11). Ciprofloxacin (CPX) was resistant to all the twenty (20) Enterobacteriaceae. Augmentin (AU) was resistant to nineteen (19) Enterobacteriaceae but susceptible to only one. Gentamycin (CN) was resistant to six (6) Enterobacteriaceae but susceptible

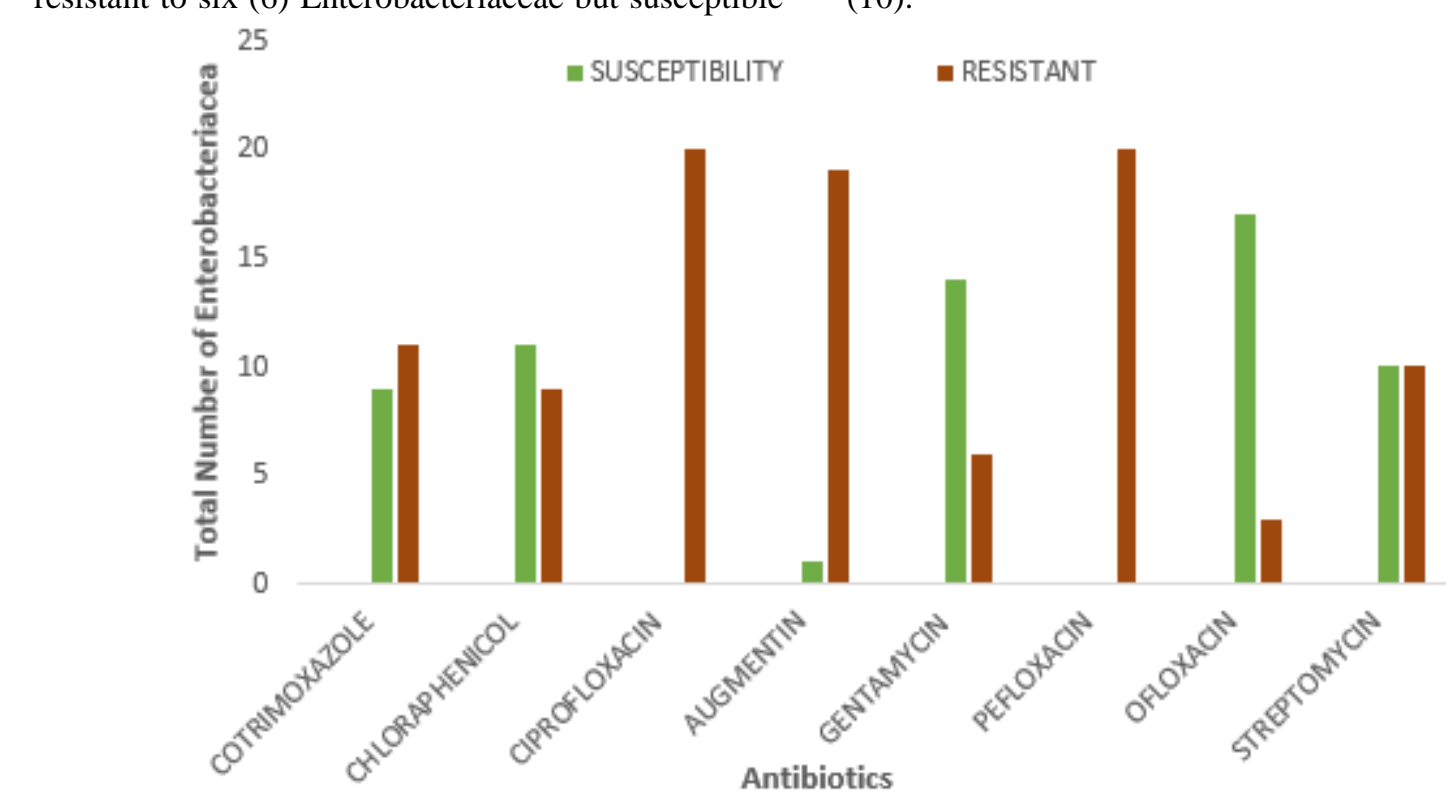

Fig 3: Frequency of Enterobacteriaceae to Antibiotics sensitivity to the other fourteen (14). Pefloxacin (PEF) was resistant to all the twenty (20) Enterobacteriaceae. Ofloxacin (OFX) was resistant to three (3) Enterobacteriaceae but susceptible to the other seventeen (17). Streptomycin (S) was resistant to ten (10) Enterobacteriaceae but susceptible to the other ten (10).
Geckos (Hemidactylus frenatus) are potential reservoirs of enteropathogens and zoonotic important bacteria. In this study, twenty (20) enteric bacteria of nine (9) different species namely Proteus mirabilis, Raoultella ornithinolytica, Enterobacter aerogenes, Salmonella ser paratyphi B, Serratia fonticola, Enterobacter kobei, Sphingomonas paucimobilis, Acinetobacter baumannii, and Burkholderia cepacia were isolated and identified. Similar bacteria genus had been identified in previous studies involving bacteria associated with Geckos. Singh et al. (2013), Nwachukwu et al. (2014), Noor et al. (2017) and Morrison and Rubin (2020) in their separate studies reported Salmonella and Proteus to be present in the faecal droppings of Geckos. Enterobacter had also been isolated and identified to be associated with Geckos (Singh et al., 2013; Nwachukwu et al., 2014, Casey et al., 2014). Noor et al. (2017) and Casey et al. (2014) have both reported Serratia as a major bacteria harbored by Geckos while Singh et al. (2013) had reported Raoultella. However, Sphingomonas, Acinetobacter and Burkholderia isolated in this study have not been previously reported to be associated with Geckos. These Enterobacteriaceae are potential threats to humans. Sphingomonas paucimobilis and Acinetobacter baumannii have been reported as human pathogens (Howard et al., 2012; Steinberg and Burd, 2015) and typically occur in immunocompromised individuals causing several infections including wound infections, meningitis, catheter-associated bacteremia, ventilator-associated pneumonia, splenic abscess etc (Martino et al., 2010). Similarly, Burkholderia cepacia has been reported to be associated to patients who have certain health challenges such as weakened immune systems or chronic lung diseases (Martino et al., 2010).

This study reported genus Enterobacter to have the highest frequency while each of Raoultella ornithinolytica, Sphingomonas paucimobilis, Acinetobacter baumannii and Burkholderia cepacia have the least frequency. This negates the work of Nwachukwu et al. (2014) and Noor et al. (2017) who reported Salmonella to have the highest frequency in their respective study on Geckos. Enterobacter aerogenes and Enterobacter kobei were recognized for their clinical significance as opportunistic bacteria and have emerged as nosocomial pathogens from intensive care patients (Mezzatesta et al., 2012). In this study, All Enterobacteriaceae were resistant to more than one antibiotics evaluated. Enterobacter aerogenes GE3 in particular was resistant to all 
antibiotics. Antibiotics resistance occurs when microorganisms develop means to defend themselves against the negative effects of specific antibiotics, hence preventing the antibiotics from effectively killing them (Puttaswamy et al., 2018). The multidrug resistance of these Enterobacteriaceae are possibly through the development of resistance genes (either intrinsic or acquired) leading to the spread of resistance from one organism to the other (Leonard et al., 2012). Ciprofloxacin (CPX) and Pefloxacin (PEF) have the highest resistance to Enterobacteriaceae while Ofloxacin (OFX) has the least resistance. This negates the work of Singh et al. (2013) and Casey et al. (2014) which showed that Cotrimoxazole (CXT) and Chloranphenicol $(\mathrm{CH})$ have the highest resistance to bacterial species.

Conclusion: Geckos (Hemidactylus frenatus) has proven to be potential reservoirs and vectors of enteropathogens and zoonotic bacteria. Enterobacteriaceae isolated from this study were resistant to most of the commercially available antibiotics; hence, the need to prevent the contamination of our food and water sources by these Geckos as well as put in place control measures to eradicate them.

\section{REFERENCES}

Ajayi JO; Ogunleye AO; Happi AN; Okunlade AO (2015). Bacteria Isolated from the Oral and Cloaca Swabs of Lizards Co-habitating with Poultry in Some Poultry Farms in Ibadan, Oyo State, Nigeria. Afr. J. Biomed. Res. 18 211- 215.

Akintokun, AK; Taiwo MO (2016). Comparison of Single Culture and the Consortium of GrowthPromoting Rhizobacteria from Three Tomato (Lycopersicon esculentum Mill) Varieties. Adv Plants and Agric. Res., 5(1).

Arnafia W; Ningrum SG; Adji RS; Lukman DW; Pasaribu FH; Wibawan IT (2016). Isolation of Salmonella from reptiles in pet shop and its susceptibility to antibiotics in Indonesia. Inter. $J$. Bioflux Soci. 8(4):177-181.

Bertone MA; Leong M; Bayless KM; Malow TLF; Dunn RR; Trautwein MD (2016). Arthropods of the great indoors: characterizing diversity inside urban and suburban homes. Peer J. 4: e1582.

Bjelland AM; Sandvik LM; Skarstein, MM; Svendal L; Debenham JJ (2020). Prevalence of Salmonella serovars isolated from reptiles in Norwegian zoos $62: 3$
Callaway Z; Thomas A; Melrose W; Buttner P; Speare R (2011). Salmonella Virchow and Salmonella Weltevreden in a Random Survey of the Asian House Gecko, Hemidactylus frenatus, in Houses in Northern Australia. Vector-Borne and Zoo. Dis. 11(6):621-625.

Casey CL; Hernandez SM; Yabsley MJ; Smith KF; Sanchez S (2014). The carriage of antibiotic resistance by enteric bacteria from imported today geckos (Gekkogecko) destined for the pet trade. 34:145-154.

Cheesbrough, M (2006). District laboratory Practice in tropical countries, part 2. Cambridge University Press. pp. 38-39, 62-71.

Fawole, MO; Oso, BA (1998). Laboratory manual of microbiology. 1st ed., Spectrum books limited, Ibadan.pp. 2528, 79-81.

Feldhaar, H (2011). Bacterial symbionts as mediators of ecologically important traits of insect hosts. Ecol. Entomol. 36, 533-543.

Gwen LO; Saleha AA (2013). Occurrence of Salmonella and other Enteric Microbes in Faeces of House Lizards (Hemidactylus frenatus). J. Vet. Malaysia. 25(1, 2):11-14.

Hakanen AJ; Lindgren M; Huovinen P; Jalava J; Siitonen A; Kotilainen P (2015). New Quinolone Resistance Phenomenon in Salmonella enterica: Nalidixic Acid-Susceptible Isolates with Reduced Fluoroquinolone Susceptibility. J. Clin. Microbiol. 43: 5775-5778.

Howard, A; O’Donoghue, H; Feeney, A; Sleator, R (2012). Acinetobacter baumannii, an emerging opportunistic pathogen. Virulence; 3(3): 243250.

Ksiazcyk, M; Kuczkowski, M; Dudek, B; Korzekwa, K; Tobiasz, A; Korzweniowska- Kowal, A; Paluch, E; Wieliczko, A; Bugla-Ploskonska, G (2016). Application of Routine Diagnostic Perocedure, VITEK 2 Compact, MALDI-TOF MS, and PCR assays in identification procedure of Bacterial strin with ambiguous phenotype. Curr Microbiol 72: 570-582.

Leonard EK; Pearl DL; Finley RL; Janecko N; ReidSmith RJ; Peregrine AS; et al. (2012). Comparison of antimicrobial resistance patterns of Salmonella spp. and Escherichia coli recovered from pet dogs from volunteer households in 
Ontario (2005-06). J Antimicrob Chemother; 67(1):174-81.

Leong M; Bertone MA; Savage AM; Bayless KM; Robert R; Trautwein MD (2017). The habitats humans provide: factors affecting the diversity and composition of arthropods in houses. Sci. Reports 7:15347.

Maina, D; Katgotho, E (2014). Suitability of Vitek-2 system in Identification and Susceptibility Testing of Gram-Negative bacteremias by direct inoculation. East Afri Med J. 91(4):115-118.

Martino R; Gomez L; Pericas R; Salazar R; Sola C; Sierra J; Garau J (2010). Bacteraemia caused by non-glucose-fermenting gram-negative bacilli and Aeromonas species in patients with haematological malignancies and solid tumours. Eur. J. Clin. Microbiol Infect. Dis. 19:320-323.

Mezzatesta, ML; Gona, F; Stefani, S (2012). Enterobacter cloacae complex: clinical impact and emerging antibiotic resistance. Future Microbiol. 7, 887-902.

Morrison, BJ; Rubin, JE (2020). Detection of multidrug-resistant Gram-negative bacteria from imported reptile and amphibian meats, J. Appl Microb. 129, 1053-1061.

Moses, IB; Ugbo, EN; Iroha, IR; Ukpai, EG; Odah, EE (2018). Antibiogram and Phenotypic Characterization of E. Coli Isolated from Nigeria's Paper Currencies obtained from Butchers in Ebonyi State. Arch Clin Microbiol 9(4):85.

Noor, AA; Nuha, KK; Aseel MHA (2017). Pathogenic bacteria isolated from Hemidactylus turcicus in Baghdad Province, Iraq J. of Ento. and Zoo. Studies 2017; 5(3): 1348-1350.

Nwachukwu, MI; Duru, MKC; Nwachukwu, IO; Anomodu, CK (2014). Incidence of Pathogenic Bacteria in Wall Gecko Dropping. Intraspecific $J$ Micro. and Life Scien. 1(1):1-6.

Ogunleye, AO; Carlson, SA (2010). Emergence of an SGI1-bearing Salmonella enterica serotype
Kentucky isolated from septic poultry in Nigeria. J. Infect. Dev. Ctries. 6(6):483-448.

Omitola, OO; Taylor-Robinson, AW (2020). Emerging and re-emerging bacterial zoonoses in Nigeria: current preventive measures and future approaches to intervention Heliyon 6 e0409.

Puttaswamy, S; Gupta, SK; Regunath, H; Smith, LP; Sengupta, S (2018). A Comprehensive Review of The Present and Future Antibiotics Susceptibility Testing (AST) Systems. Archives of Clin. Micro. Vol 9: iss No 3:83.

Singh, BR; Singh, V; Ebibeni, N; Singh, RK (2013). Antimicrobial and herbal drug resistance in enteric Bacteria isolated from faecal Droppings of common house Lizard/ gecko (Hemidactylus fenatus). Int. J. of Micro. 16:21-27

Steinberg, JP; Burd, EM (2015). Gram negative and Gram variable BaCILLI in Mandell, Douglas, and Bennett's Principles and Practice of Infectious Diseases (8th Edition), 2015.

Wani, N; Suhail, M; Kakru, D; Bali, N; Kohli, A; Ahmad, J (2016). Comparison of automated Vitek-2 with conventional methods for Identification, and Antibiotic Sensitivity in Gram Negative Organisms. Micro. Res. J. Int. 14(2): 18 .

Whiley, H; McLean, R; Ross, K (2017). Detection of Campylobacter jejuni in Lizard Faeces from Central Australia Using Quantitative PCR. Pathogens. 6(1):1-6.

World Health Organization (WHO) (2018). Salmonella (non-typhoidal): World Health Organization. 2018. https ://www.who.int/newsroom/fact-sheet s/ detai 1/salmo nella -(non-typho idal). Accessed September, 2020.

Yakubu, Y; Junaidu, AU; Magaji, AA; Salihu, MD; Mahmuda, A; Shehu, S (2011). One Health — the fate of public health in Nigeria, Asian J. Med. Sci. 3 (1) $47-49$. 